\title{
SALINIZATION PROCESS AND INFLUENCING FACTORS IN WESTERN JILIN PROVINCE, CHINA
}

\author{
BAO, S. C. $.^{*}-$ QIU, Y.Y. ${ }^{1}-$ WANG, Q. ${ }^{2}-$ WANG, Z. J. ${ }^{3}$ \\ ${ }^{1}$ School of Civil Engineering, Jilin Jianzhu University \\ No.5088 Xincheng Street, Changchun, Jilin, China \\ (phone: +86-135-9647-1419; fax: +86-0431-8456-6417) \\ ${ }^{2}$ College of Construction Engineering, Jilin University \\ No.6 Ximinzhu Street, Changchun, Jilin, China \\ ${ }^{3}$ Jilin Team of Geological Survey Center of China Building Materials Industry \\ No.6 Ximinzhu Street, Changchun, Jilin, China \\ ${ }^{*}$ Corresponding author \\ e-mail:baoshuochao@126.com \\ (Received $3^{\text {rd }}$ Aug 2019; accepted $14^{\text {th }}$ Nov 2019)
}

\begin{abstract}
Saline soil is widely distributed in western Jilin province, China, agriculture and engineering are affected by the saline soil. Its formation and development process are influenced the most by factors of the natural geological environment. For the purpose of investigating the salinization process and influence factors in western Jilin, this study analyzes the saline soil of Nong'an in western Jilin Province, which was sampled during a field investigation. Thereafter, the characteristics of the water and salt migration in the soil have been investigated in the laboratory, the environmental factors of the study area, and the influence of the ecological environment on salinization have also been discussed. The results show that the water and salt migrate with seasonal changes in soil. The water content is low in autumn, and high in spring and summer. The salt content of the soil near the ground surface is low in autumn, and high in spring and summer, meanwhile, the salt content in the deep soil layers is low in spring and autumn, and high in summer. During both the unfrozen period and the frost-thawing periods, the soil salinization continues to enhance, and salinization eventually causes land desertification. This study can provide the theoretical basis for the protection of fragile ecological environments.
\end{abstract}

Keywords: saline soil, soil enviroment, salinization process, secological environment, desertification

\section{Introduction}

Saline soil is widely distributed in western Jilin province, China, which has caused decline in soil fertility and reduction in grain production (Wang, 1993). Further, the saline soil has also caused several engineering problems, such as road sinking, salt heaving and corrosion. In western Jilin, agricultural and engineering works are affected by saline soil. Western Jilin is located in a seasonally frozen ground area, in which the formation and process of development are influenced by the especial natural geological environment of the area.

According to earlier studies, the formation of saline soil in western Jilin is caused by the natural conditions and aggravated by the human activities (Wang et al., 2011; Zhang et al., 2013; Xu and Dou, 2013). Zhang and Li (2000) considered Songnen plian salinization development was exacerbated by the unreasonable land exploitation by humans, which caused secondary salinization. Yang and Luo (1999) studied the dynamic characteristics relationship between Songnen plain soil salinization and the underground water characteristics. He concluded that the salty underground water was a major 
contributor to the formation of the saline soil on the Songnen plain. Liu (2001) monitored the water and salt content movements of the saline soil in the Hongqi irrigation area in Songnen plain, China. Zheng (2005) discussed the driving force for the water and salt accumulation in winter. Wang et al. (2011) named the saline soil in western Jilin as dispersive soil and analyzed the influence factors of dispersibility and frost heaving characteristics. Bao et al. (2018) took laboratory test of salin soil in west Jilin to find out $t$ the frost-heaving rate of soil.

This study aims to investigate the saline soil in Nong'an area of western Jilin, China. In this study, laboratory tests have been carried out to determine the characteristics of the soil samples. The environmental factors of the study area have also been analyzed, and the salinization process in western Jilin has been discussed. The results of this study can be used as a theoretical foundation of salinization treatment in western Jilin and the whole Songnen plain.

\section{Material and Methods}

The soil samples were collected from Nong'an area in western Jilin province, China. The study area is located in north of Song'nen plain in China, which is a typical temperate continental semiarid and arid monsoon climate area. This region has severe cold winters and torrid summers, with low annual precipitation. Based on the local salinizated distribution characteristics, two representative sampling locations have been chosen,

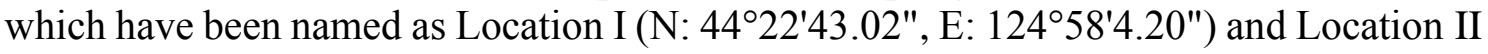
$\left(\mathrm{N}: 44^{\circ} 22^{\prime} 26.88^{\prime \prime}, \mathrm{E}: 125^{\circ} 0^{\prime} 52.56^{\prime \prime}\right)$. The sampling locations are shown in Fig. 1.



Figure 1. Sampling locations

The ground surface of Location I was dry ang barely grass covered (Fig. 2). The ground surface of Location II was grassland which is mostly covered by green grass in summer (Fig. 3). For the purpose of comparing the salinization processs, the soil samples were collected in May, June, September and November in 2015. The collected samples were at the depths of $0 \mathrm{~cm}, 20 \mathrm{~cm}, 30 \mathrm{~cm}, 40 \mathrm{~cm}$ from the ground surface.

The natural water content, salt content were tested in laboratory of soil samples to investigate the water and salt migration law of saline soil of western Jilin, then the 
environmental factors of the study area have also been investigated to analysis the salinization process. According to earlier studies, the salinization of western Jilin was due to the strong evaporation effect of the earth's surface (Chen, 2013; Kusmiyati, 2014; Wang et al., 2015). The evaporation effect is influenced by natural facotors such as temperture and rainfall, so this study choose 3 environment factors as temperture, precipitation and evaporation to discusse the salinaztion process. The enviroment data was investaged and processed from Chinameteorological Data Sharing Service System of China (CDSSSC).

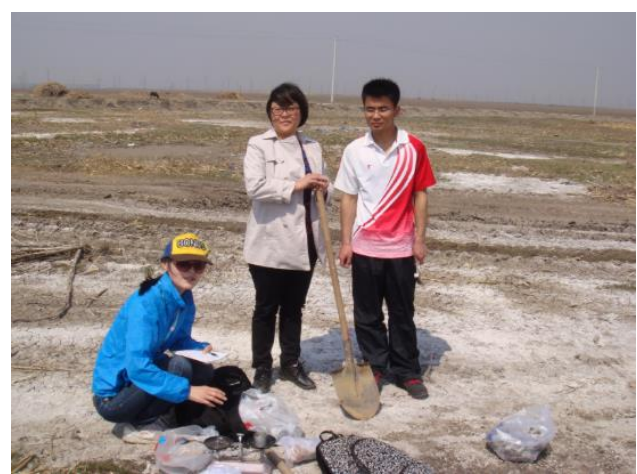

Figure 2. Location I

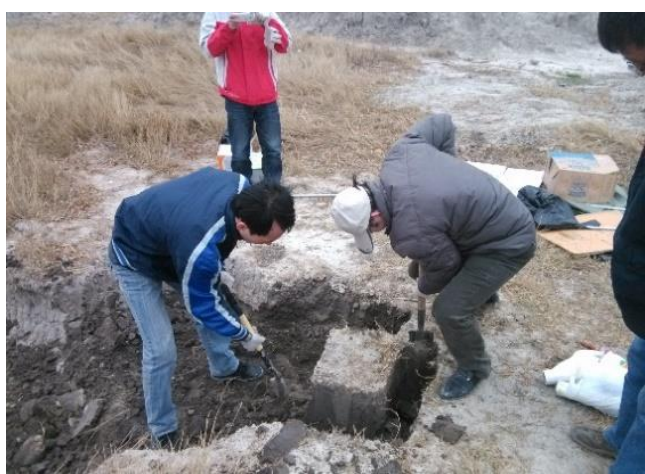

Figure 3. Location II

\section{Results}

\section{Water content seasonal variations}

The soil samples were first weighed at the sampling location, and then dried in the laboratory in order to gain the natural water content. Water content was caluted by Formula 1.

$$
W=\left(\frac{m_{0}}{m_{d}}-1\right) \times 100 \%
$$

where

$W$ - water content of soil, $\%$.

$m_{d}$ - mass of dry soil, $\mathrm{kg}$.

$m_{0}$ - mass of wet (natural) soil, $\mathrm{kg}$.

The water content variations with depths are shown as Fig. 4.

As shown in Fig. 4, natural water contens of soil water are between 5.0\% 34.1\%, water migrates with depth, but the migration laws are quite different in diffent seasons. For the purpose of studing the water seasonal migration law, water content seasonal variations of the soil samples at two locations are shown as Fig. 5.

As shown in Fig. 4 and Fig. 5, for the soil samples at the two locations, the water contents are high in spring and summer, and low in autumn. For the soil samples near the ground surface, the water contents are low in spring, highest in summer, and then fall in autumn. For the soil samples at 20-30 cm depth, the water contents are highest in spring, and fall in summer. The gradients of the water seasonal variation curves are large in this range, and the water contents fall in autumn. For the soil samples at $40 \mathrm{~cm}$ depth, the water contents are relatively constant, which means that the water contents of these 
samples are about the same in spring and summer, but they are lower in autumn. Hence, it can be concluded that seasonal rainfall affect the soil near the ground surface more than that deep underground. Further, the surface soil always shows the variation of being dry in spring and autumn, and wet in summer as influenced by the short-term rainfall.
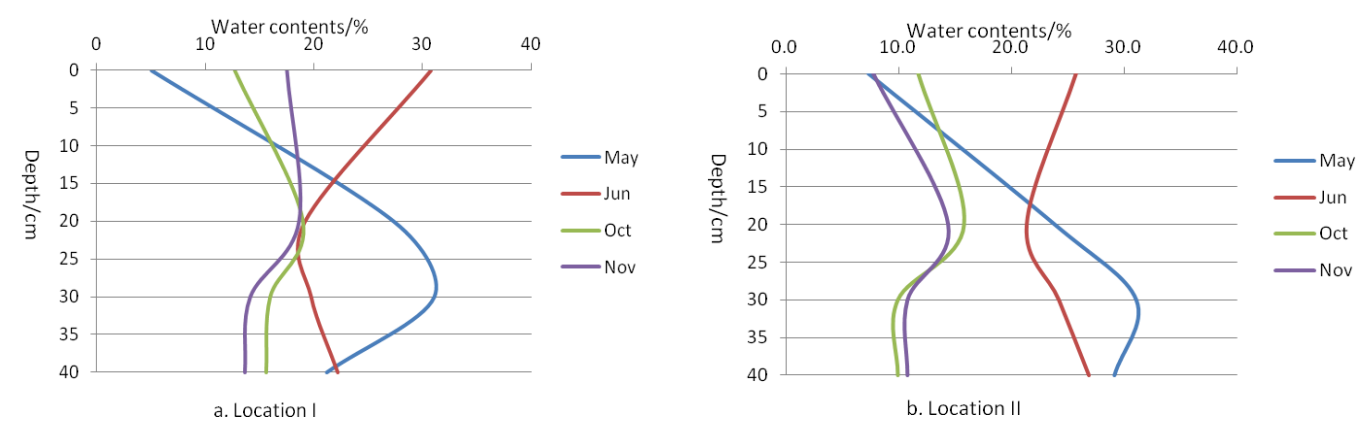

Figure 4. Water content of soil samples at two locations
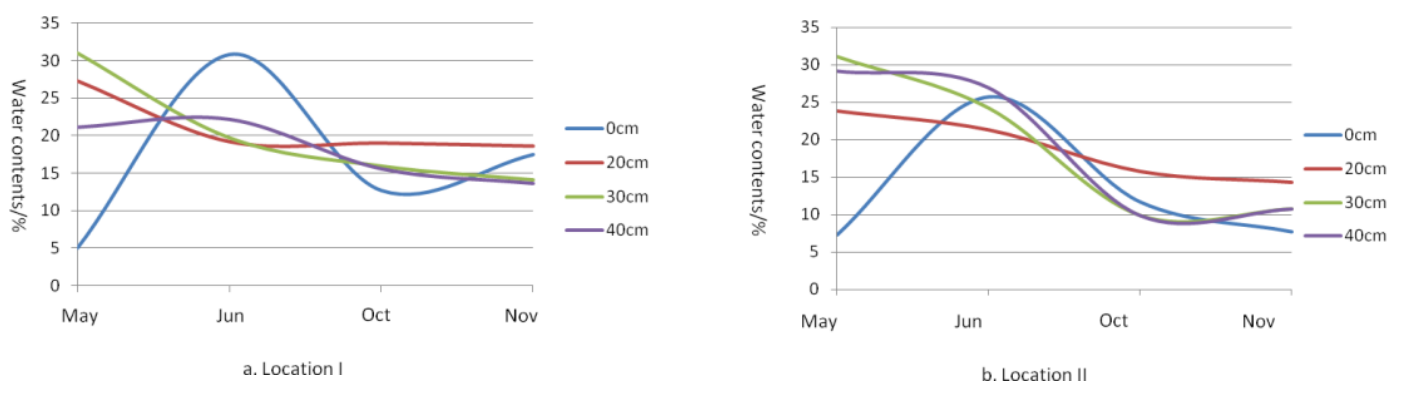

Figure 5. Water content seasonal variations of soil samples at two locations

\section{Salt content seasonal variations}

The salt contents of the soil samples have been tested by the distillation method, salt content variations with depths are shown as Fig. 6.

As shown in Fig. 6, salt migrates with depth in general. But the migration law are not only different between 2 locations, but also different in different seasons. For the purpose of studing the salt seasonal migration law, the salt content seasonal variations of the soil samples at two locations and at different depths are shown in Fig 7.

As shown in Fig. 6 and Fig. 7, except for the soil samples near the ground surface, the salt contents of the soil samples at the other depth are all higher in summer, and lower in spring and autumn. Thus, for these soil samples, the salt content seasonal variations show a " $n$ " shape. However, the salt content seasonal variations of the soil samples near the ground surface show an inverse "n" shape, i.e., "u" shape. The salt content of a soil obviously changes with season, and weather affects the salt accumulation in the soil, which varies with season and soil depth.

Meanwhile, the composition of salt in soil were tested by titration and flame photometry methods. The test results are shown as Table 1 .

As shown in Table 1, the $\mathrm{Na}^{+}$contents are high and other positive ion are relatively low of soil samples. The salinization types can be determined by calculating the $\mathrm{Cl}^{-} / \mathrm{SO}_{4}{ }^{2}$ 
or $\left(\mathrm{CO}_{3}{ }^{2-}+\mathrm{HCO}_{3}{ }^{-}\right) /\left(\mathrm{Cl}^{-}+\mathrm{SO}_{4}{ }^{2-}\right)$. When meet the Formula 2 or Formula 3, the soil can be named as carbonate saline soil.

$$
\begin{gathered}
\mathrm{A}=\mathrm{Cl}^{-} / \mathrm{SO}_{4}{ }^{2-}<0.3 \\
\mathrm{~B}=\left(\mathrm{CO}_{3}{ }^{2-}+\mathrm{HCO}_{3}{ }^{-}\right) /\left(\mathrm{Cl}^{-}+\mathrm{SO}_{4}{ }^{2-}\right)>0.3
\end{gathered}
$$

According to Table 1, since the $\mathrm{SO}_{4}{ }^{2-}$ of all samples are 0 , it can only be calculated as $\mathrm{B}$ value using Formula 2. After calculating the datas from Table 1, the B values of soil samples are between 0.31-1.67, soil samples of study area are carbonate saline soil.
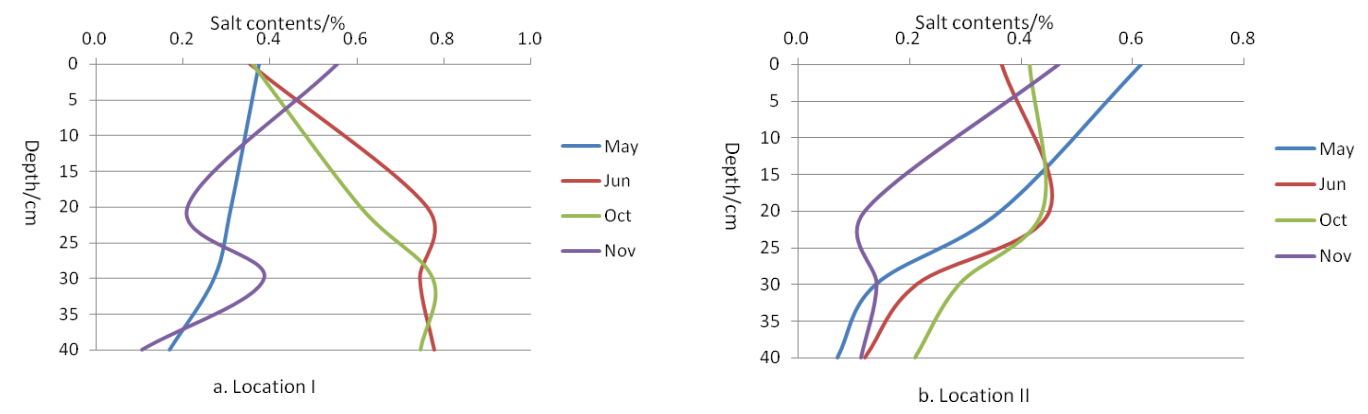

Figure 6. Salt content of soil samples at two locations
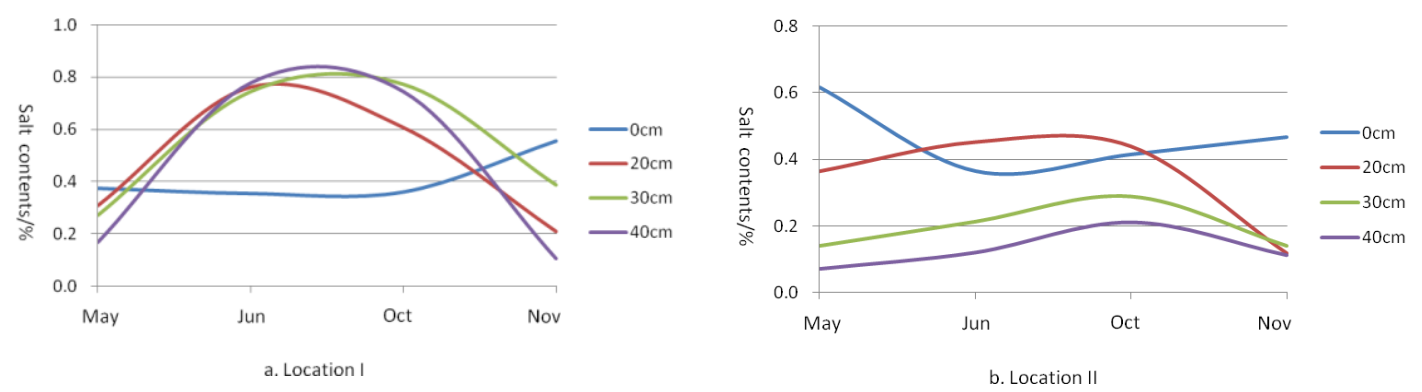

Figure 7. Salt content seasonal variations of soil samples at two locations

The salinization progress and salinization types are relevant to local environment. Therefore, it is necessary to research both the environmental and climatic factors in the investigation of the salinization progress of soil in western Jilin.

The changes in seasonal climate and environment affect evaporation, eluviations and frost-thawing. These changes produce different driving force in moving the water in soil in different directions, i.e. water migration. Further, as salt is dissolved in water, it also migrates with the water in the soil. Different environmental processes cause the migration in different directions and the accumulation of salt in different amounts.

Weather environment has an important influence on the migration of water and salt, accumulation and transportation of saline soil in western Jilin. It is the driving force of saline soil's formation. 
Table 1. Ion contents of soil samples

\begin{tabular}{|c|c|c|c|c|c|c|c|c|c|c|}
\hline \multirow{2}{*}{ Locations } & \multirow{2}{*}{ Time } & \multirow{2}{*}{ Depth/cm } & \multicolumn{8}{|c|}{ Ion contents/(mmol/100g) } \\
\hline & & & $\mathbf{K}^{+}$ & $\mathrm{Na}^{+}$ & $\mathbf{C a}^{2+}$ & $\mathbf{M g}^{2+}$ & $\mathrm{CO}_{3}^{2-}$ & $\mathrm{HCO}_{3}^{-}$ & $\mathrm{Cl}^{-}$ & $\mathrm{SO}_{4}{ }^{2-}$ \\
\hline \multirow{16}{*}{ I } & \multirow{4}{*}{ May } & 0 & 0.02 & 3.62 & 0.01 & 0 & 0 & 0.07 & 0.05 & 0 \\
\hline & & 20 & 0.02 & 3.01 & 0.01 & 0.01 & 0 & 0.01 & 0.03 & 0 \\
\hline & & 30 & 0.01 & 2.63 & 0 & 0.01 & 0 & 0.01 & 0.02 & 0 \\
\hline & & 40 & 0.02 & 1.72 & 0.01 & 0.01 & 0 & 0.01 & 0.02 & 0 \\
\hline & \multirow{4}{*}{ June } & 0 & 0.01 & 4.36 & 0.02 & 0.01 & 0 & 0.01 & 0.03 & 0 \\
\hline & & 20 & 0.01 & 6.89 & 0.01 & 0.01 & 0 & 0.01 & 0.03 & 0 \\
\hline & & 30 & 0.02 & 6.35 & 0.01 & 0 & 0.03 & 0.01 & 0.03 & 0.03 \\
\hline & & 40 & 0.01 & 6.22 & 0.01 & 0 & 0 & 0.01 & 0.02 & 0 \\
\hline & \multirow{4}{*}{ October } & 0 & 0.02 & 4.52 & 0.01 & 0.01 & 0 & 0.01 & 0.02 & 0 \\
\hline & & 20 & 0.01 & 5.68 & 0.01 & 0.01 & 0 & 0.02 & 0.01 & 0 \\
\hline & & 30 & 0.01 & 6.74 & 0.01 & 0.01 & 0 & 0.01 & 0.04 & 0 \\
\hline & & 40 & 0.01 & 6.13 & 0.01 & 0 & 0 & 0.01 & 0.06 & 0 \\
\hline & \multirow{4}{*}{ November } & 0 & 0.02 & 5.46 & 0.02 & 0.02 & 0 & 0.01 & 0.02 & 0 \\
\hline & & 20 & 0.01 & 2.38 & 0.01 & 0.01 & 0 & 0.01 & 0.03 & 0 \\
\hline & & 30 & 0.02 & 3.36 & 0.01 & 0 & 0 & 0.01 & 0.03 & 0 \\
\hline & & 40 & 0.02 & 1.17 & 0.01 & 0 & 0 & 0.01 & 0.04 & 0 \\
\hline \multirow{16}{*}{ II } & \multirow{4}{*}{ May } & 0 & 0.01 & 6.03 & 0 & 0 & 0.01 & 0 & 0.04 & 0.01 \\
\hline & & 20 & 0.02 & 3.49 & 0.02 & 0 & 0 & 0.01 & 0.01 & 0 \\
\hline & & 30 & 0.02 & 1.28 & 0 & 0.01 & 0 & 0 & 0.01 & 0 \\
\hline & & 40 & 0.01 & 1.03 & 0.01 & 0.01 & 0 & 0.01 & 0.01 & 0 \\
\hline & \multirow{4}{*}{ June } & 0 & 0.02 & 3.72 & 0.01 & 0.01 & 0.01 & 0.01 & 0.02 & 0.01 \\
\hline & & 20 & 0.02 & 4.29 & 0.01 & 0.01 & 0 & 0.01 & 0.01 & 0 \\
\hline & & 30 & 0.02 & 2.05 & 0.01 & 0 & 0 & 0.01 & 0.01 & 0 \\
\hline & & 40 & 0.01 & 1.16 & 0.01 & 0 & 0 & 0 & 0 & 0 \\
\hline & \multirow{4}{*}{ October } & 0 & 0.02 & 4.09 & 0.02 & 0 & 0 & 0.02 & 0.03 & 0 \\
\hline & & 20 & 0.01 & 4.1 & 0 & 0.01 & 0 & 0.03 & 0.09 & 0 \\
\hline & & 30 & 0.01 & 2.73 & 0.01 & 0 & 0 & 0.02 & 0.06 & 0 \\
\hline & & 40 & 0.02 & 1.97 & 0.01 & 0 & 0 & 0.02 & 0.05 & 0 \\
\hline & \multirow{4}{*}{ November } & 0 & 0.02 & 4.48 & 0.01 & 0.01 & 0.01 & 0.01 & 0.01 & 0.01 \\
\hline & & 20 & 0.02 & 1.15 & 0.01 & 0.01 & 0.01 & 0.01 & 0.04 & 0.01 \\
\hline & & 30 & 0.01 & 1.24 & 0.01 & 0 & 0.01 & 0.01 & 0.04 & 0.01 \\
\hline & & 40 & 0.01 & 1.02 & 0.01 & 0.01 & 0.01 & 0.01 & 0.03 & 0.01 \\
\hline
\end{tabular}

\section{Temperature factors in wester Jilin}

The daily temperature of Nong'an during 2003-2013 ten years has been analyzed (CDSSSC). These data have been organized into average monthly temperature, as shown in Fig. 8.

As shown in Fig. 8, western Jilin has four distinctive seasons. The monthly average temperature varies between $19.55^{\circ} \mathrm{C}$ and $23.06^{\circ} \mathrm{C}$. The monthly average temperature in January is the lowest, and in July is the highest. From January to December, the temperature varies in a parabola shape. The four seasons in western Jilin can be concluded 
by the variations in the temperature, i.e. April to May is spring, June to August is summer which has the highest temperature, September to October is autumn, and winter is from November to next March, which is the longest season in western Jilin. The average temperatures for the four months in winter are always below $0^{\circ} \mathrm{C}$. As a conclusion, western Jilin has hot summer, frigid and long winter, which causes the soil to freeze in winter and thaw in spring. The frost and thawing processes cause the water and salt to migrate with a temperature gradient. Further, during an unfrozen season, the evaporation and elucidation in spring, summer and winter affect the soil salinization process. So, these two factors should also be investigated.



Figure 8. Average monthly temperature of Nong'an

\section{Precipitation factors in wester Jilin}

The daily rainfall precipitation of Nong'an during 2003-2013 has been analyzed (CDSSSC). These data have been organized into average monthly precipitation, as shown in Fig. 9.

As shown in Fig. 9, in the last ten years, the average annual precipitation is $523.07 \mathrm{~mm}$. The main rainfall months are May to August, which receive $73.74 \%$ of the precipitation for whole year. The highest precipitation is in July, which is $27.11 \%$ of the precipitation for the whole year. The rainfall is low in January to March, especially in January. These data show that summer is short in western Jilin, but the elucidation caused by rainfall cannot be ignored in a salinization study.

\section{Evaporation factors in wester Jilin}

In order to compare the effects of precipitation and evaporation, the evaporation during 2003-2013 has also been analyzed (CDSSSC). Fig. 10 shows the average monthly precipitation and evaporation.

As shown in Fig. 10, the average annual evaporation is $1104 \mathrm{~mm}$, which is much higher than the average annual precipitation. The evaporation amount is quite different from the precipitation amount, which is high in March to October. Evaporation is highest in April, which is $16.53 \%$ of the evaporation for the whole year. The evaporation effect is influenced by the especial climatic characteristics in western Jilin as windy springtime. 
As shown in Fig. 10, the precipitation and evaporation differ significantly in spring and autumn. Evaporation has a major effect on the water in the soil. In summer, precipitation and evaporation are about the same. Only in July, the precipitation amount is higher than the evaporation amount.

In conclusion, western Jilin has an arid and semi-arid monsoon climate, which has high temperature and rainy in summer, windy spring and autumn, cold and long winter, and the annual evaporation amount is much higher than the precipitation amount. This especial climate characteristic provides the condition for salt accumulation on the ground surface. The soluble salt produced by rock wreathing during the soil formation period migrates and accumulates with water at different directions with frost effect in winter, evaporation effect in spring and autumn, and precipitation effect in summer. Eventually, the soil is salinized.

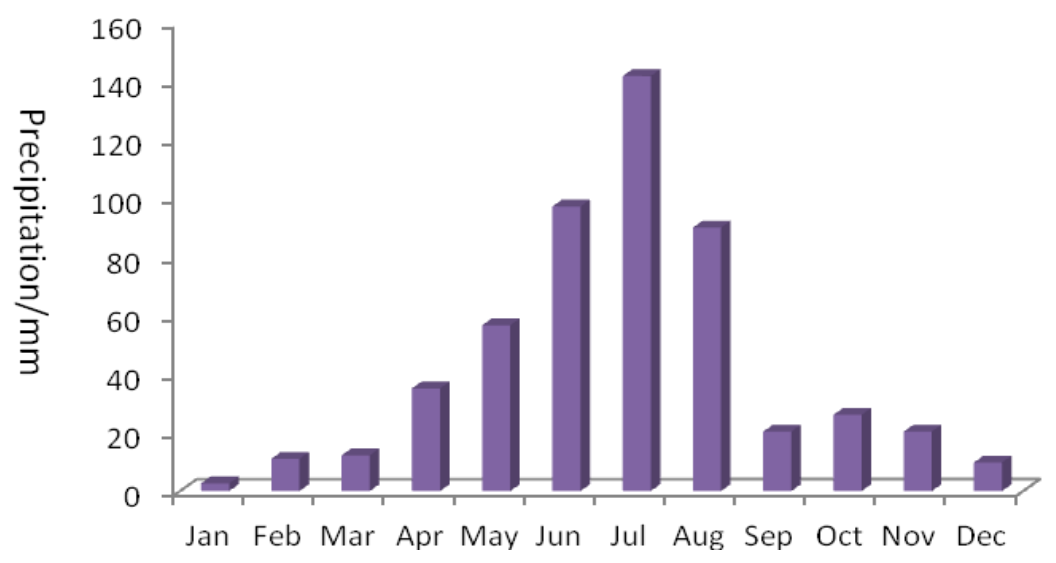

Figure 9. Average monthly precipitation of Nong'an

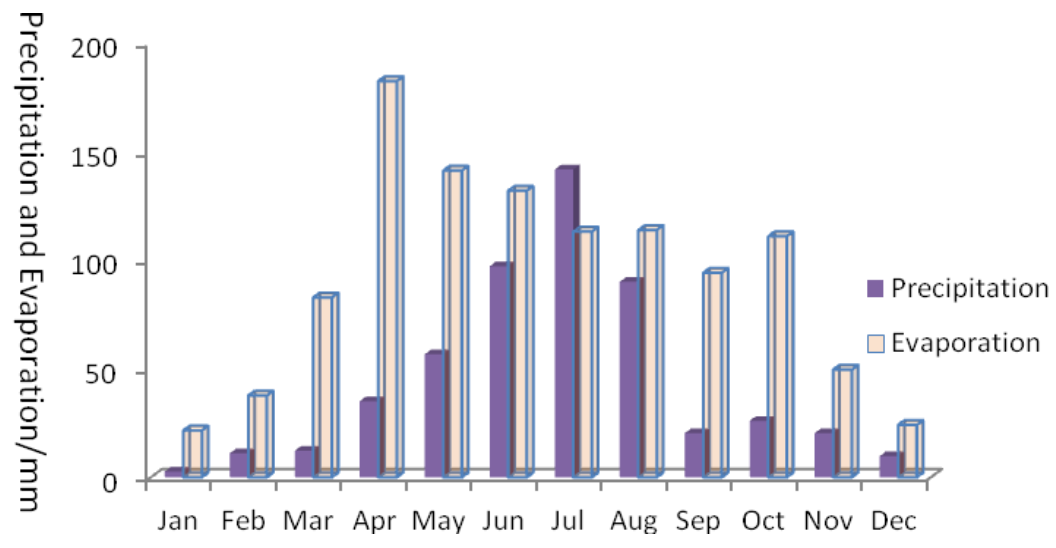

Figure 10. Average monthly precipitation and evaporation of Nong'an

\section{Discussions}

According to the analyses in Section 3, different seasons have different climatic conditions, which cause the water and salt in the soil to have different movements. The salinization process during unfrozen period and frost-thawing period is discussed in this section. 


\section{Water and salt migration in unfrozen period}

According to the water and salt migration curves (Fig. 5 and Fig. 7), the salt accumulation in western Jilin is uncontinuous, which is influenced by the seasons, i.e. spring and autumn are the salification period, and summer is the desalination period.

Accoding to Fig. 4 and Fig. 6, firstly, the initial salt in soil comes from soluble salt produced by parent rock wreathing effect, this salt dissolves into water during rainy season and migrates from high terrain areas to low terrain areas. This is why most saline soil is distributed in the low terrain areas. However, during a rainy season, little salt is accumulated on the ground surface as it migrates with direct surface runoff (Fig. 7), in which most of the salt is leached with water to the soil deep underground. So, the salt and water migrate downward during this period, and there is little salt accumulated on the ground surface.

By the end of rainy seasons, dry seasons begin, and the evaporation effect comes in during this period. The evaporation effect provides the driving force for the water to flow from the ground surface the deep soil (Fig. 4), in which salt migrates with soil upwards. The surface water evaporates into air, causing the salt to stay in the soil. Hence, salt accumulates near the ground surface as Fig. 6 shown. As time passes, soil becomes salinized.

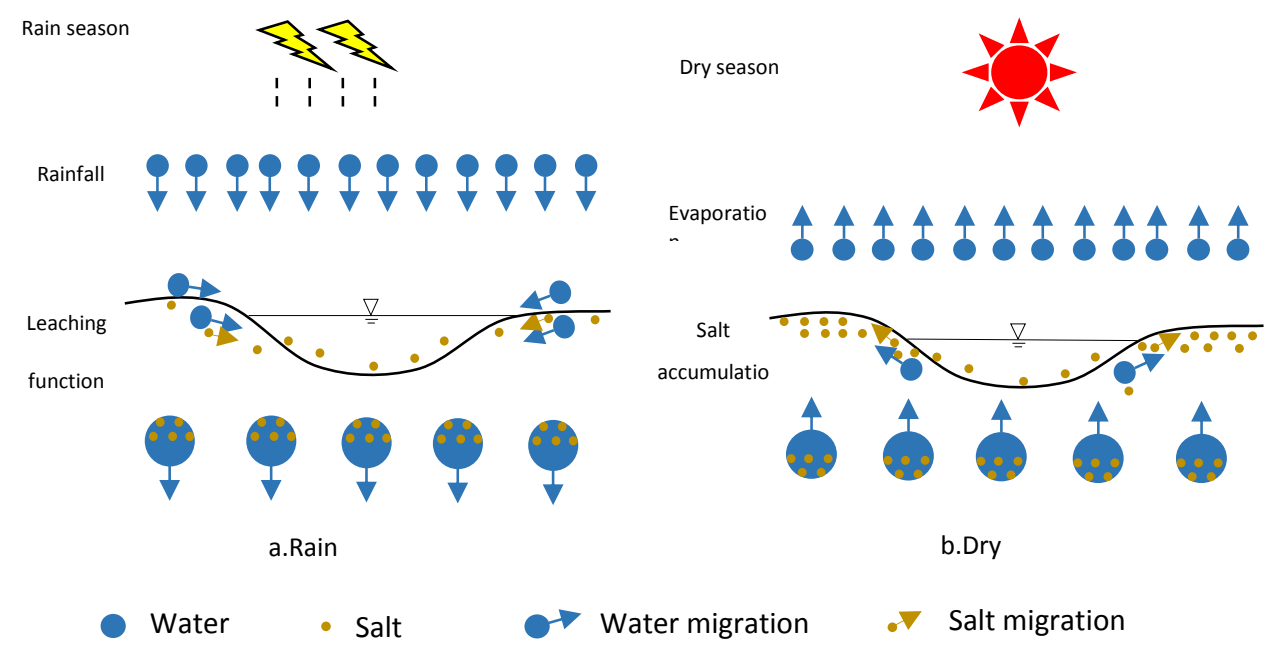

Figure 11. Salt migration during unfrozen periods

In conclusion, although salt accumulates in dry season and desalinizes in rainy season during unfrozen period which makes the soil salinization process discontinuous. However, according to the former discussions, the salification effect is much stronger than desalination effect. Therefore, salt is still accumulated in long term and the soil in western Jilin is still saline. Gradually over time, the soil becomes more saline.

\section{Water and salt migration in frost-thawing period}

Based on the Fig. 8, western Jilin has long winters. So, the soil goes through long freezing periods, and then thaws at spring. During the freezing period, according to the temperature gradient, frost is formed on the soil surface (Jozef and Katarina, 2014). So, the freezing depth increases gradually. In the frozen soil, free water freezes into ice. 
Hence, it cannot migrate freely in the soil. But some unfrozen water becomes bound water. The freezing point of this strong bound water is $-78^{\circ} \mathrm{C}$ (Bouyoucos, 1920). The freezing point of the loose bound water is between $-20^{\circ} \mathrm{C}$ and $-30^{\circ} \mathrm{C}$ (Fig. 12). This bound water in western Jilin cannot be freezed. The bound water can still migrate due to the temperature gradient effect, which is from high temperature to low temperature. Therefore, during the frost period, the direction of water migration is upwards. Salt that is dissolved in the bound water can also migrate upwards with it.



Figure 12. Freezing points of free and bound water

Salt migration requires a supply source. During the freezing process in winter, the frozen frontal moves downwards continually. Hence, the distance between the unfrozen soil layer and the underground water level becomes smaller and smaller. Finally, the distance becomes less than maximum that the underground water can rise to. The salt in the underground water therefore migrates into the frozen soil layer. Under this circumstance, the salt comes from the underground water that migrates towards the frozen frontal surface, which makes the salty underground water stays in the pores of soil as ice. Meanwhile, some salt in the soil dissolves into water during the underground water movement. Besides, salt migrates also requires a driving force. Salt in the frozen soil layer crystallizes during the freezing process, causing the solution concentration in the soil's pores to change. Since the extents of freezing of whole soil freezing profile are different, as well as the degrees of salt crystallization are different, which results in a potential gradient in the pore solution. Salt migrates with unfrozen water upwards driven by the temperature gradient and solution potential gradient.

When spring comes, soil starts to melt from frozen top layer and bottom layer at the same time. During the melting process, some soluble salt comes from the melting snow water, rainfall water and irrigation water migrates into the soil. Further, between the frozen layer and the unfrozen layer, there is a potential gradient in the solution. Moreover, the ground surface temperature is getting higher during this period, the solubility of water in the top soil layer is getting greater, which is the condition for carrying more salt. That's why Fig. 7 shows the law that salt contents are high in spring. Based on the climatic characteristics of western Jilin, the rainfall is low in February to April. During spring in western Jilin, the evaporation capacity is much higher than precipitation. This causes the migration rate in spring to be higher and water evaporates faster, which enhances the soil salinization process. 


\section{Ecological environment influnces of salinization in western Jilin province}

According to the analyses in Section 4.2 and 4.3, salinization process enhanced during forzen and unfrozen periods effected with seasonal environmental conditions. Salinization function can cause land dererioration and ecological system gets fragile, which can harm the agriculture, engineering and ecological enviroment. In recnt years, annually financial loss reached up to 8.9 million RMB caused by salination in northeast China (Lin, 2016).

Western Jilin is locted in south Songnen plain, which is the crucial agriculture production area in China. Soil salinization deduced productivity of land, according to Lin (2016), since the 1950s, 22\% land turned into salinization and desertification of Songnen plain, the ecological deterioration rates in western Jilin are shown as Fig. 13. As those rates, the 1/2 land will turn to desert of western Jilin.

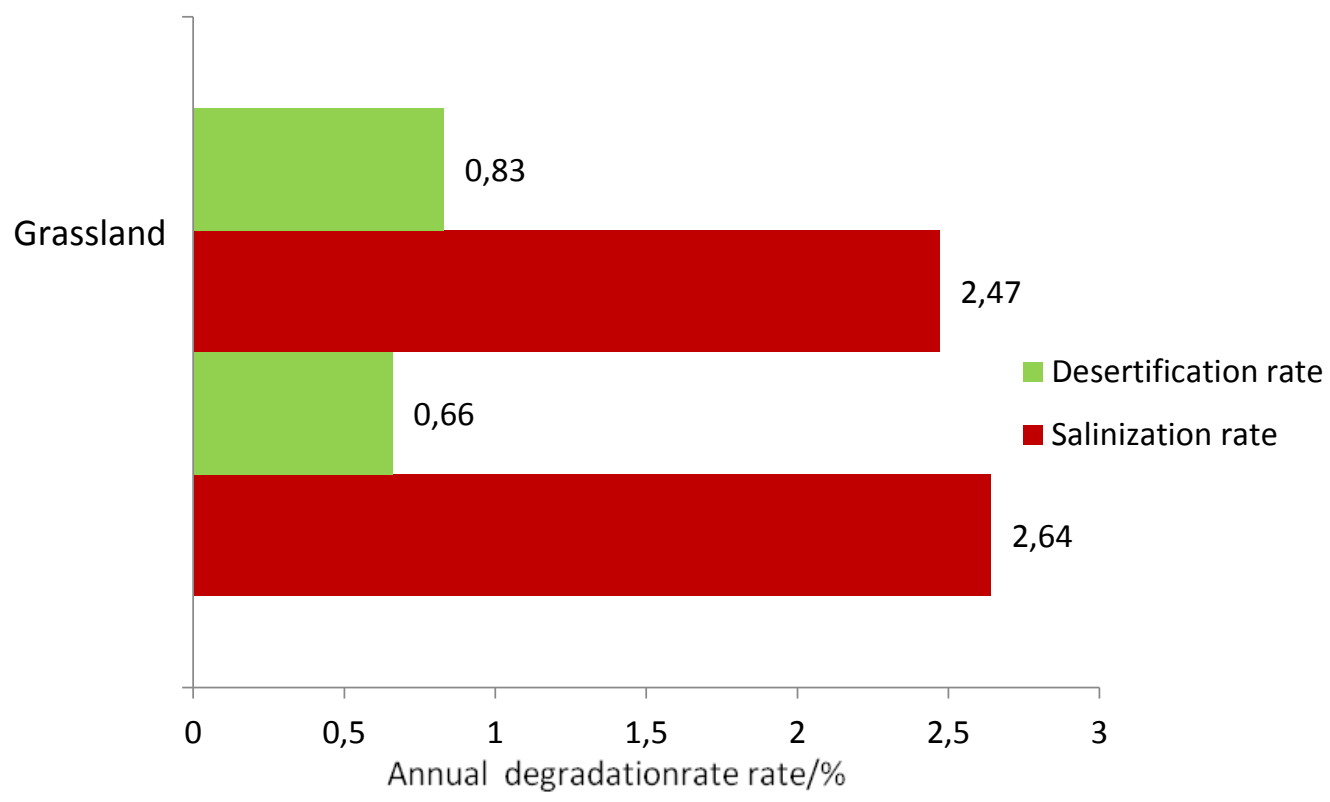

Figure 13. Ecological deterioration rates of wester Jilin

Based the analyses above, Fig. 14 shows the salinization process in western Jilin. Soil salinization destroys ecological system, changes physical behavior and chemical component of soil, deduces nurient of soil, causes the productivity decline, as the result, land turns desertification eventually.

According to earlier studies, saline soil was caused by weather conditions. Zhou and Zhao (1979) considered the harmful climatic conditions that aggravate the salinization progress are spring drought and summer waterlogging. Xu and Dou (2013) considered flooding tillage method causing underground water level to rise increased the degree of salinization. Most of the earlier studies discussed salinization progress in the unfrozen period. In this study, water migration and salt migration have been tested to provide the basic data to show the migration process in soil, and the salinization progress has been discussed particularly during the unfrozen period and the frost-thawing period. Discussion of the salization fuction and process of Jilin province in this sudy can provide the theoretical basis of fragile ecological enviroment protection. 


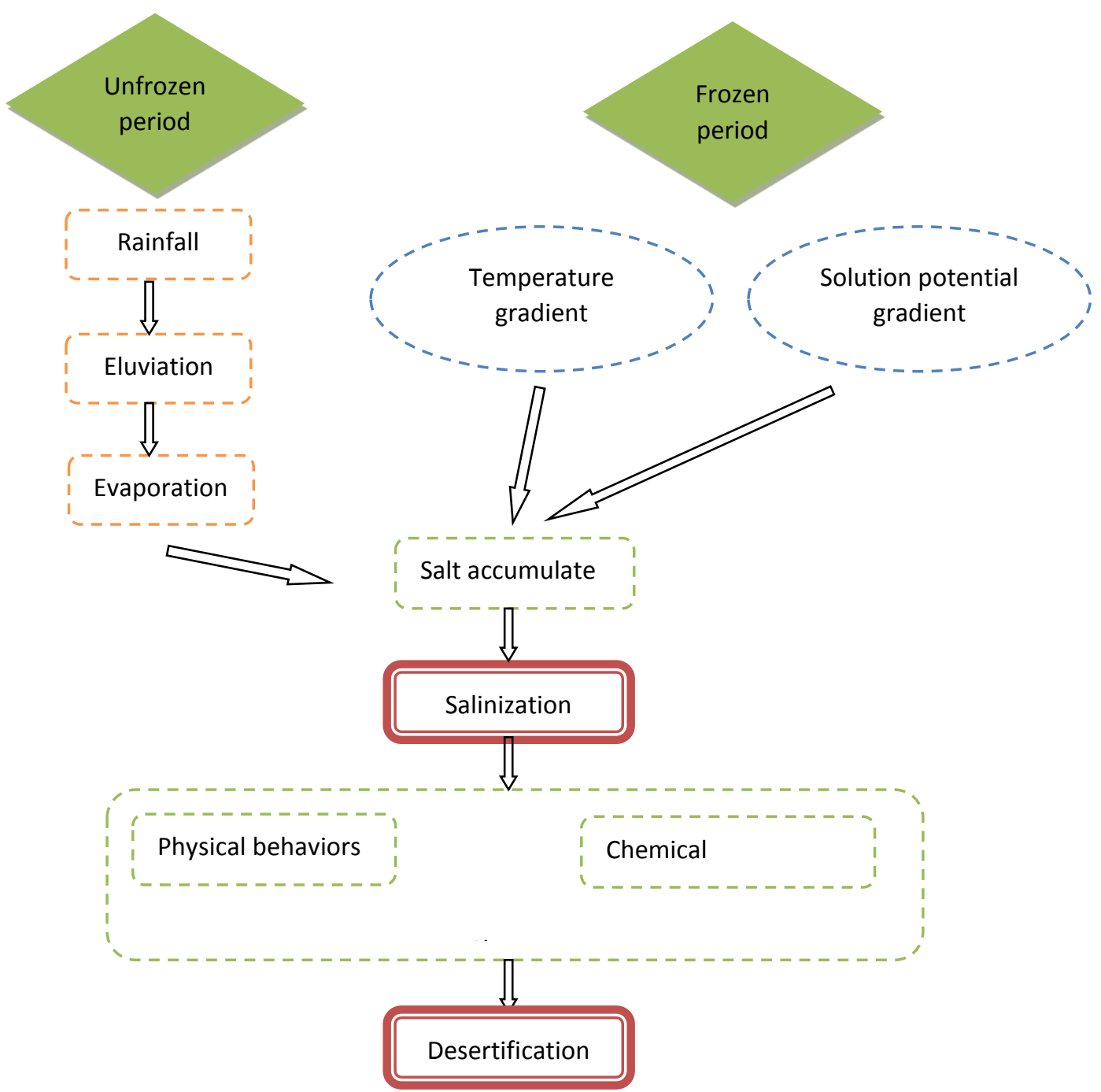

Figure 14. Salinization process in western Jilin

\section{Conclusions}

In this study, the saline soil water and salt migration characteristics and the environmental characteristics in western Jilin in relation to the salinization progress have been investigated. The conclusions are:

a. Water in soil migrates with seasonal changes, the water content is high in spring and summer, and low in autumn. Salt in soil also migrates with seasonal changes. The salt content of the soil near the ground surface is high in spring and summer, and low in autumn. However, the salt content of deep soil layer is low in spring and autumn, and low in summer.

b. Soil salinization continues to develop both in unfrozen period and frost-thawing period. During the unfrozen period, the process is: rainfall $\rightarrow$ direct surface runoff movements $\rightarrow$ salt goes into soil with eluviation function $\rightarrow$ evaporation $\rightarrow$ salt migrates upwards and accumulates.

c. During the unfrozen period, underground water supplies soil's water and salt. Salt migrates upwards driven by the temperature gradient and solution potential gradient, which enhances soil salinization progress in western Jilin. 
$\mathrm{d}$. The salinization progress is related to the environmental characteristics of western Jilin. Therefore, the salinization prevention in western Jilin should focus on ecological environment management, and the engineering should focus on frost-heaving prevention in western Jilin. This conclusion has great significance for the agriculture and engineering developments in western Jilin province, China.

e. There are other environmental variables such as the groundwater level, soil parameters furthermore the irrigation strategy could influence the salt concentration, which should be tested in further study. So it will be draw more comprehensive conclusion due to further study.

Acknowledgements. This work was supported by Jilin Province Science and Technology Development Projects (grant number: No. 20180520063JH), Scientific Research project of Jilin Province Department of Education (grant number: JJKH20190867KJ), Research and Development Project of the Ministry of Housing and Urban-rural Development (2018-K9-009).

\section{REFERENCES}

[1] Bao, S. C., Wang, Q., Bian, J. M., Li, M., Wang, Z. J. (2018): Characteristics and laboratory freeze-thaw test of saline soil in west Jilin, China. - Applied Ecology an Environmental Reserch 16(1): 511-520.

[2] Bouyoucos, G. (1920): Degree of temperature to which soils can be cooledwithout freezing. - Monthly Weather Review 48(12): 718-718.

[3] Chen, Y. (2013): Study on irrigation and discharge schedules for ameliorating saline-sodic soils in paddies on irrigation districts of the Songnen Plain. - University of Chinese Academy of Sciences, Beijing.

[4] Chinameteorological data sharing service system of China. - http: //cdc.cma.gov.cn/.

[5] Jozef, K., Katarina, G. (2014): Soil monitoring system as a basic tool for protection of soils and sustainable land use in Slovakia. - Jornal of Agricultural Science and Technology 4(6): 504-513.

[6] Kusmiyati, F. (2014): Effect of mulch and mixed cropping grass- legume at saline soil on growth, forage yield and nutritional quality of guinea grass. - Journal of the Indonesian Tropical Animal Agriculture 10: 72-78.

[7] Lin, N. F. (2016): Biology-Soil system comprehensive development and utilization. - Jilin University Press, Changchun.

[8] Liu, J. (2001): Studies on the principles of water and salt movement and secondary salinization in Songnen plain. - Northeast Agricultural University 3: 22-25.

[9] Wang, Z. Q. (1993): Saline soil in China. - Science Press, Beijing.

[10] Wang, W. H., Wang, Q., Zhang, J. (2011): An experiment study of the fundamental property of the carbonate-saline soil in sest of Jilin province. - Journal of Beijing University of Technology 37(2): 217-224.

[11] Wang, Z. L., Fu, Q., Meng, J., Wang, X. H., Wang, X. W. (2015): Analysis on variations of black soil water in Songnen plain during ice and snow thaqing periods. - South-to-north water transfers and water science \& technology 13(1): 173-175.

[12] Xu, B. Y., Dou, S. (2013): Problems and Suggestions in land consolidation in songyuan city. - China Agriculture Information 7: 200-201.

[13] Yang, J. X., Luo, X. X. (1999): Study on the relationship between soil salinization and groundwater dynamics. - Water and Soil Conservation Bulletin 7(6): 1-11.

[14] Zhang, D. F., Li, F. Q. (2000): Mechanism of formation of fragile eco-geo-environment of agro-pastoral zigzag zone in northern China. - Rural Eco-environment 16(4): 58-62. 
[15] Zhang, H. Q., Wang, L. X., Sun, G. Y. (2013): Evaluation of saline-alkali land resource and development potential in low Songnen plains. - Chinese Journal of Agricultural Resources and Regional Planning 34(2): 7-11.

[16] Zheng, D. M. (2005): Study on the temporal rhythm of water and salt transference of alkalization soil in Songnen Plain. - Northeast Normal University, Changchun.

[17] Zhou, Y. C., Zhao, H. S. (1979): Study on soil moisture dynamics in songnen plain. Journal of Soil 3: 302-305. 